\title{
Editorial: Proceedings of the "Fourth International Conference of the FMR1 Premutation: Basic Mechanisms, Clinical Involvement and Therapy"
}

\author{
Karen Usdin ${ }^{1}$, Laia Rodriguez-Revenga ${ }^{2}$, Rob Willemsen ${ }^{3}$, Renate Hukema ${ }^{3}$ and \\ Cecilia Giulivi ${ }^{4,5 *}$ \\ ${ }^{1}$ Gene Structure and Disease Section, Laboratory of Cell and Molecular Biology, National Institute of Diabetes, Digestive and \\ Kidney Diseases, National Institutes of Health, Bethesda, MD, United States, ${ }^{2}$ Biochemistry and Molecular Genetics \\ Department, Hospital Clinic of Barcelona and CIBER of Rare Diseases (CIBERER), Instituto de Salud Carlos III, Barcelona, \\ Spain, ${ }^{3}$ Department of Clinical Genetics, Erasmus MC, Rotterdam, Netherlands, ${ }^{4}$ Department of Molecular Biosciences, \\ School of Veterinary Medicine, University of California, Davis, Davis, CA, United States, ${ }^{5}$ The MIND Institute, University of \\ California, Davis Medical Center, Sacramento, CA, United States
}

Keywords: FMR1 premutation, triplet nucleotide repeats, AGG interruptions, FXTAS, FXPOI, mouse model, mitochondrial dysfunction

\section{Editorial on the Research Topic}

Proceedings of the "Fourth International Conference of FMR1 Premutation: Basic Mechanisms, Clinical Involvement and Therapy"

OPEN ACCESS

Edited and reviewed by:

Luigi Michele Pavone,

University of Naples Federico II, Italy

${ }^{*}$ Correspondence:

Cecilia Giulivi

cgiulivi@ucdavis.edu

Specialty section:

This article was submitted to

Cellular Biochemistry,

a section of the journal

Frontiers in Molecular Biosciences

Received: 24 February 2021

Accepted: 29 March 2021

Published: 27 April 2021

Citation:

Usdin K, Rodriguez-Revenga L, Willemsen $R$, Hukema $R$ and Giulivi $C$ (2021) Editorial: Proceedings of the "Fourth International Conference of

the FMR1 Premutation: Basic

Mechanisms, Clinical Involvement and

Therapy".

Front. Mol. Biosci. 8:671875.

doi: 10.3389/fmolb.2021.671875
Fragile $X$ mental retardation 1 (FMR1) is an X-linked gene with a hypervariable CGG repeat tract in its 5' UTR. Alleles with 55-200 CGG repeats are known as premutation alleles (Kogan et al., 2008). Alleles with $>200$ repeats, known as full mutation alleles, are responsible for Fragile $\mathrm{X}$ syndrome, the most common inherited form of intellectual disability and autism spectrum disorder (Verkerk et al., 1991; Yu et al., 1991). The repeat tract in premutation alleles expands on intergenerational transmission to produce larger premutation or full mutation alleles. However, the mechanism responsible for this expansion is largely unknown. Premutation alleles, once thought to be asymptomatic, are now known to confer risk of developing Fragile X-associated tremor/ataxia syndrome (FXTAS), a neurodegenerative disorder (Jacquemont et al., 2003; Grigsby et al., 2006) and a form of ovarian dysfunction known as Fragile X-associated primary ovarian insufficiency (Sherman, 2000; Wittenberger et al., 2007). Premutation carriers can also have other symptoms including fibromyalgia, chronic fatigue, and sleep problems that are referred to collectively as the Fragile X-Associated Neuropsychiatric Disorders (Hagerman et al., 2018). The molecular basis of the pathology seen in premutation carriers is still the subject of much debate (Glineburg et al., 2018).

This special collection of Frontiers in Cell and Developmental Biology contains contributions from leading groups in this field that were presented at the 4th International Conference of the FMR1 Premutation held in Rotterdam on September 25-27, 2019 organized by Drs. Renate Hukema and Rob Willemsen. This collection covers recent advances in basic and clinical research into the underlying mutation and pathology associated with the FMR1 premutation.

\section{MECHANISMS OF EXPANSION AND DISEASE PATHOLOGY}

Gazy et al. showed that embryonic stem cells from FMR1 premutation mice (Entezam et al., 2007) recapitulate expansion in a dish, thus providing the first cell model that can be used to 
study expansion mechanisms. As in cells from human premutation carriers, these cells show mitochondrial abnormalities (Napoli et al., 2016), an FMR1-associated Rloop (Groh et al., 2014; Loomis et al., 2014; Kumari and Usdin, 2016) and elevated Fmr1 transcription (Tassone et al., 2000). Interestingly, increased transcription was sensitive to $\mathrm{O}_{2}$ tensions. Since these cells can be readily gene-edited, they may help expedite studies of the expansion mechanism as well as premutation pathology.

One model for premutation pathology proposes that RAN translation from premutation alleles produces toxic proteins including FMRpolyGlycine (FMRpolyG), that are responsible both for disease pathology and the intranuclear neuronal inclusions that are a hallmark of FXTAS (Krans et al., 2019). Two papers in this issue address the issue of the role of FMRpolyG. Haify et al. describes an inducible mouse model of FXTAS containing the 5' UTR of the human FMR1 gene with 103 CGG repeats cloned downstream of a dox-inducible CamKII- $\alpha$ promoter. This allowed the regulated expression of FMRpolyG by doxycycline. However, after 12 weeks of FMRpolyG induction no evidence of a behavioral phenotype was seen despite the presence of many intranuclear inclusions throughout the brain. Thus, neither inclusions nor the expression of FMRpolyG per se are sufficient to cause neurological problems, at least in young adult mice.

Holm et al. describe the analysis of the cerebral cortex proteome in individuals with FXTAS. Significant differences from the normal proteome were observed including decreased tenascin-C (TNC) and increased levels of the small ubiquitinlike modifier 1/2 (SUMO1/2). FMRpolyG, which has only been identified in trace amounts in studies of FXTAS inclusions (Ma et al., 2019), was not identified in either FXTAS or control brains. Interestingly, in contrast to many other neurodegenerative diseases, the proteome of end-stage FXTAS provides no evidence for a strong inflammation-mediated degenerative response.

\section{CLINICAL INVOLVEMENT IN FMR1 PREMUTATION CARRIERS}

Johnson et al. report on the recommendations of the European Fragile X Network, made in consultation with other stakeholders at the meeting, that the term Fragile X Premutation Associated Conditions (FXPAC) be used to encompass all conditions related to the premutation. This recommendation was made in part to avoid stigmatization of carriers and to facilitate patient evaluation and treatment.

Two papers address metabolic alterations in premutation carriers. Cao et al. review the altered metabolites identified in previous studies of plasma from premutation carriers and the cerebella of FXTAS mice. Napoli et al. address the metabolic footprint of plasma from female carriers using a combined multi-omics approach. Down-regulation of RNA and mRNA metabolism, protein translation, carbon and protein metabolism and the unfolded protein response, and up-regulation of glycolysis and the antioxidant response were observed. Some changes were linked to decreased protein translation, but others seemed to be secondary to oxidative stress.

Finally, Tassanakijpanich et al. discuss rarely appreciated cardiovascular problems in premutation carriers and possible contributing mechanisms including RNA toxicity and mild FMRP deficiency. The review underscores cardiac arrhythmia, autonomic dysfunction, and hypertension as problems that clinicians need to be aware of in this population.

\section{MOTOR AND NEUROCOGNITIVE PROFILE OF FMR1 PREMUTATION CARRIERS}

Although FXTAS is more prevalent and severe in males than females, specific sex differences have not been well-documented. In this section, Loesch et al. report a 2-fold faster progression in males than in females in key measures of tremor and ataxia, while psychiatric symptoms only progressed in females. They postulate the existence of neuroprotective effects beyond the presence of one normal FMR1 allele in female carriers, specifically affecting cerebellar circuitry.

Winston et al. describe patterns of visual attention in premutation carriers, parents of individuals with autism spectrum disorders, and typically developing controls. Their results demonstrate a visual attention profile that appears strongly associated with the premutation in women and that thus may constitute a meaningful biomarker. Mailick et al. compared the response to parenting stress in mothers with "low zone" ( $\mathrm{LZ} ; \leq 25 \mathrm{CGGs)}$ ) alleles to mothers whose repeats were in the normal range. LZ mothers who had children with disabilities had greater limitations in executive functioning, depression, anxiety, daily health symptoms, and balance, than LZ mothers of non-disabled children. In contrast, mothers with normal-range CGG repeats did not differ based on stress exposure consistent with greater resilience.

\section{ANALYSIS OF CGG REPEAT ALLELES}

Villate et al. report the analysis of 87 maternal transmissions of alleles with 45-65 repeats and variable numbers of AGG interruptions. Their results confirm the protective effect of AGGs reported previously (Nolin et al., 2013). The authors suggest that assessment of the risk of unstable transmissions should be based on the presence or absence of AGG interruptions and not on the classical cutoffs that define different FMR1 alleles. Rodrigues et al. described a new approach for evaluating normal FMR1 alleles that includes the contribution from the AGG interspersion pattern of each allele. The outcome, a numerical parameter named "allelic score," describes the allelic complexity of the FMR1 gene and provides an additional tool to evaluate pathogenicity and expansion risk. 


\section{CONCLUDING REMARKS AND FUTURE DIRECTIONS}

The studies published in this special collection demonstrate just how far our understanding of the pathogenic mechanisms, disease diagnosis and management of affected individuals has come in the few years since the 3rd International Meeting on the FMR1 Premutation. However, these studies also highlight the work that still needs to be done to

\section{REFERENCES}

Entezam, A., Biacsi, R., Orrison, B., Saha, T., Hoffman, G. E., Grabczyk, E., et al. (2007). Regional FMRP deficits and large repeat expansions into the full mutation range in a new Fragile X premutation mouse model. Gene 395, 125-134. doi: 10.1016/j.gene.2007.02.026

Glineburg, M. R., Todd, P. K., Charlet-Berguerand, N., and Sellier, C. (2018). Repeat-associated non-AUG (RAN) translation and other molecular mechanisms in Fragile X Tremor Ataxia Syndrome. Brain Res. 1693, 43-54. doi: 10.1016/j.brainres.2018.02.006

Grigsby, J., Brega, A. G., Jacquemont, S., Loesch, D. Z., Leehey, M. A., Goodrich, G. K., et al. (2006). Impairment in the cognitive functioning of men with fragile $\mathrm{X}$-associated tremor/ataxia syndrome (FXTAS). J. Neurol. Sci. 248, 227-233. doi: 10.1016/j.jns.2006.05.016

Groh, M., Lufino, M. M., Wade-Martins, R., and Gromak, N. (2014). Rloops associated with triplet repeat expansions promote gene silencing in Friedreich ataxia and fragile X syndrome. PLoS Genet. 10:e1004318. doi: 10.1371/journal.pgen.1004318

Hagerman, R. J., Protic, D., Rajaratnam, A., Salcedo-Arellano, M. J., Aydin, E. Y., and Schneider, A. (2018). Fragile X-Associated Neuropsychiatric Disorders (FXAND). Front. Psychiatry 9:564. doi: 10.3389/fpsyt.2018.00564

Jacquemont, S., Hagerman, R. J., Leehey, M., Grigsby, J., Zhang, L., Brunberg, J. A., et al. (2003). Fragile X premutation tremor/ataxia syndrome: molecular, clinical, and neuroimaging correlates. Am. J. Hum. Genet. 72, 869-878. doi: $10.1086 / 374321$

Kogan, C. S., Turk, J., Hagerman, R. J., and Cornish, K. M. (2008). Impact of the Fragile X mental retardation 1 (FMR1) gene premutation on neuropsychiatric functioning in adult males without fragile X-associated Tremor/Ataxia syndrome: a controlled study. Am. J. Med. Genet. B Neuropsychiatr. Genet. 147B, 859-872. doi: 10.1002/ajmg.b.30685

Krans, A., Skariah, G., Zhang, Y., Bayly, B., and Todd, P. K. (2019). Neuropathology of RAN translation proteins in fragile $\mathrm{X}$-associated tremor/ataxia syndrome. Acta Neuropathol. Commun. 7:152. doi: 10.1186/s40478-019-0782-7

Kumari, D., and Usdin, K. (2016). Sustained expression of FMR1 mRNA from reactivated fragile $\mathrm{X}$ syndrome alleles after treatment with small molecules that prevent trimethylation of H3K27. Hum. Mol. Genet. 25, 3689-3698. doi: $10.1093 / \mathrm{hmg} / \mathrm{ddw} 215$

Loomis, E. W., Sanz, L. A., Chedin, F., and Hagerman, P. J. (2014). Transcriptionassociated R-loop formation across the human FMR1 CGG-repeat region. PLoS Genet. 10:e1004294. doi: 10.1371/journal.pgen.1004294 improve our understanding and treatment of these disorders. Hopefully, some of these issues will be addressed at the 5th iteration of this conference scheduled for New Zealand in March 2022.

\section{AUTHOR CONTRIBUTIONS}

All authors listed have made a substantial, direct and intellectual contribution to the work, and approved it for publication.

Ma, L., Herren, A. W., Espinal, G., Randol, J., Mclaughlin, B., Martinez Cerdeno, V., et al. (2019). Composition of the intranuclear inclusions of fragile X-associated Tremor/Ataxia Syndrome. Acta Neuropathol. Commun. 7:143. doi: 10.1186/s40478-019-0796-1

Napoli, E., Song, G., Wong, S., Hagerman, R., and Giulivi, C. (2016) Altered bioenergetics in primary dermal fibroblasts from adult carriers of the FMR1 premutation before the onset of the neurodegenerative disease fragile X-associated tremor/ataxia syndrome. Cerebellum 15, 552-564. doi: 10.1007/s12311-016-0779-8

Nolin, S. L., Sah, S., Glicksman, A., Sherman, S. L., Allen, E., Berry-Kravis, E., et al. (2013). Fragile X AGG analysis provides new risk predictions for 45-69 repeat alleles. Am. J. Med. Genet. A 161A, 771-778. doi: 10.1002/ajmg.a.35833

Sherman, S. L. (2000). Premature ovarian failure in the fragile X syndrome. Am. J. Med. Genet. 97, 189-194. doi: 10.1002/1096-8628(200023)97:3andlt;189::AIDAJMG1036andgt;3.0.CO;2-J

Tassone, F., Hagerman, R. J., Taylor, A. K., Gane, L. W., Godfrey, T. E., and Hagerman, P. J. (2000). Elevated levels of FMR1 mRNA in carrier males: a new mechanism of involvement in the fragile-X syndrome. Am. J. Hum. Genet. 66, 6-15. doi: $10.1086 / 302720$

Verkerk, A. J., Pieretti, M., Sutcliffe, J. S., Fu, Y. H., Kuhl, D. P., Pizzuti, A., et al. (1991). Identification of a gene (FMR-1) containing a CGG repeat coincident with a breakpoint cluster region exhibiting length variation in fragile X syndrome. Cell 65, 905-914. doi: 10.1016/0092-8674(91)90397-H

Wittenberger, M. D., Hagerman, R. J., Sherman, S. L., Mcconkie-Rosell, A., Welt, C. K., Rebar, R. W., et al. (2007). The FMR1 premutation and reproduction. Fertil. Steril. 87, 456-465. doi: 10.1016/j.fertnstert.2006.09.004

Yu, S., Pritchard, M., Kremer, E., Lynch, M., Nancarrow, J., Baker, E., et al. (1991). Fragile X genotype characterized by an unstable region of DNA. Science 252, 1179-1181. doi: 10.1126/science.252.5009.1179

Conflict of Interest: The authors declare that the research was conducted in the absence of any commercial or financial relationships that could be construed as a potential conflict of interest.

Copyright (c) 2021 Usdin, Rodriguez-Revenga, Willemsen, Hukema and Giulivi. This is an open-access article distributed under the terms of the Creative Commons Attribution License (CC BY). The use, distribution or reproduction in other forums is permitted, provided the original author(s) and the copyright owner(s) are credited and that the original publication in this journal is cited, in accordance with accepted academic practice. No use, distribution or reproduction is permitted which does not comply with these terms. 